Pacific Journal of Mathematics

THE SPECTRA OF ENDOMORPHISMS OF THE DISC 


\section{THE SPECTRA OF ENDOMORPHISMS OF THE DISC ALGEBRA}

\section{HERBERT KAMOWITZ}

In this note the spectra of certain endomorphisms of the disc algebra $A$ are determined. Those endomorphisms $T$ of $A$ given by $T f=f \circ \varphi$ for some $\varphi \in A$ with $\varphi$ having a fixed point $z_{0}$ in the open unit disc are considered and it is shown that either the spectrum $\sigma(T)$ of $T$ is the closed unit disc, or else $\sigma(T)$ is the closure of $\left\{\left(\varphi^{\prime}\left(z_{0}\right)\right)^{n} \mid n\right.$ is a positive integer $\} \cup$ $\{1\}$.

By an endomorphism of an algebra $B$ we mean a linear map $T$ of $B$ into itself satisfying $T(f g)=(T f)(T g)$ for all $f, g \in B$. We denote by $\sigma(T)$ those complex numbers $\lambda$ for which $(\lambda-T)^{-1}$ does not exist.

Throughout this note $A$ will denote the sup-norm algebra of functions continuous on the closed unit disc and analytic on the open unit disc. If $T(\neq 0)$ is a endomorphism of $A$, then there is a function $\varphi$ in the unit ball of $A$ for which $T f=f \circ \varphi$ for all $f \in A$. Indeed, if $z$ is the identity function in $A$, then $\varphi=T z$. We call $T$ the endomorphism of $A$ induced by $\varphi$. Clearly $\sigma(T)$ depends on $\varphi$.

We remark that it follows from Schwarz's Lemma that if a function $\varphi \in A,\|\varphi\| \leqq 1$ has more than one fixed point in the open unit disc, then $\varphi(z)=z$ for all $z,|z| \leqq 1$. It is well-known, however, that such $\varphi \in A$ can have infinitely many points on the unit circle with $\varphi(z)=z$ and yet $\varphi$ need not be equal to the identity function $z$.

We begin by showing that if $\varphi$ has a fixed point $z_{0}$ in the open unit disc, it is no restriction to assume that $z_{0}=0$.

LEMma 1. Let $\varphi \in A,\|\varphi\| \leqq 1$ and $T$ be the endomorphism of $A$ induced by $\varphi$. Suppose $\left|z_{0}\right|<1$ and $\varphi\left(z_{0}\right)=z_{0}$. Let $g$ be the linear fractional transformation $g(z)=\left(z_{0}-z\right) /\left(1-\bar{z}_{0} z\right)$ and $T^{\prime}$ the endomorphism of $A$ induced by $\psi=g \circ \varphi \circ g$. Then $\psi(0)=0, \psi^{\prime}(0)=\varphi^{\prime}\left(z_{0}\right)$ and $\sigma\left(T^{\prime}\right)=\sigma(T)$.

Proof. The map $\mathscr{C}: f(z) \rightarrow f\left(\left(z_{0}-z\right) /\left(1-\bar{z}_{0} z\right)\right)$ is an isometry of $A$ onto itself, and so $\sigma(T)=\sigma\left(\mathscr{U}^{-1} T \mathscr{U}\right)=\sigma\left(T^{\prime}\right)$. It is a routine verification that $\psi(0)=0$ and $\phi^{\prime}(0)=\phi^{\prime}\left(z_{0}\right)$.

When $T$ is an automorphism (a $1-1$ onto endomorphism) of $A$, then the spectrum of $T$ is easy to determine. Indeed, if $\varphi$ is the function which induces $T$, then $\varphi$ is a schlicht mapping of the disc onto itself. By Lemma 1 we may assume that $\varphi(0)=0$. Then $\varphi$ 
has the form $\varphi(z)=c z$ for some $c,|c|=1$. Now, for each positive integer $k, c^{k}$ is an eigenvalue of $T$ because $T\left(z^{k}\right)=(\varphi(z))^{k}=(c z)^{k}=$ $c^{k} z^{k}$, and so either $c^{n}=1$ for some positive integer $n$ in which case $T^{n}=I$ and $\sigma(T)=\left\{1, c, \cdots, c^{n-1}\right\}$ or else, if $c$ is not a root of unity, then $\sigma(T)=\{\lambda|| \lambda \mid=1\}$.

Definition. Let $\varphi \in A$ with $\|\varphi\| \leqq 1$. If $k$ is a nonnegative integer, we denote the $k^{\text {th }}$ iterate of $\varphi$ by $\varphi_{k}$. That is, $\varphi_{0}(z)=z$ and $\varphi_{k}(z)=\varphi\left(\varphi_{k-1}(z)\right),|z| \leqq 1$. Furthermore, we will call $\bigcap_{k}$ range $\left(\varphi_{k}\right)$ the fixed set of $\varphi$.

Straightforward topological arguments show that the fixed set of $\varphi$ is a compact, connected subset of the unit disc and that $\varphi$ maps its fixed set onto itself.

For the endomorphisms we are considering, the spectra will depend on the fixed set of the inducing maps.

Lemma 2. Let $\varphi \in A,\|\varphi\| \leqq 1, \varphi(0)=0$ and $T$ be the endomorphism of $A$ induced by $\varphi$. Then $\sigma(T) \supset\left\{\left(\varphi^{\prime}(0)\right)^{n} \mid n\right.$ is a positive integer $\}$.

Proof. The assertion is clearly true if $T$ is an automorphism or if $\varphi^{\prime}(0)=0$. For the case $0<\left|\varphi^{\prime}(0)\right|<1$, we show that for each positive integer $k,\left(\left(\varphi^{\prime}(0)^{k}-T\right) f \neq z^{k}\right.$ for all $f \in A$.

For, suppose $f \in A$ and $\left(\varphi^{\prime}(0)\right)^{k} f-f(\varphi)=z^{k}$. Then

$$
\left(\varphi^{\prime}(0)\right)^{k} f^{\prime}(z)-f^{\prime}(\varphi(z)) \varphi^{\prime}(z)=k z^{k-1}
$$

At $z=0,\left(^{*}\right)$ becomes $\left(\phi^{\prime}(0)\right)^{k} f^{\prime}(0)-f^{\prime}(0) \varphi^{\prime}(0)=0$, or $f^{\prime}(0)=0$.

Further,

$\left({ }^{* *}\right) \quad\left(\varphi^{\prime}(0)\right)^{k} f^{\prime \prime}(z)-f^{\prime \prime}(\varphi(z))\left(\varphi^{\prime}(z)\right)^{2}-f^{\prime}(\varphi(z)) \varphi^{\prime \prime}(z)=k(k-1) z^{k-2}$.

At $z=0,\left(^{* *}\right)$ becomes $\left(\varphi^{\prime}(0)\right)^{k} f^{\prime \prime}(0)-f^{\prime \prime}(0)\left(\varphi^{\prime}(0)\right)^{2}-f^{\prime}(0) \phi^{\prime \prime}(0)=0$, and since we already have $f^{\prime}(0)=0$, we obtain $\left(\phi^{\prime}(0)\right)^{k} f^{\prime \prime}(0)-f^{\prime \prime}(0)\left(\phi^{\prime}(0)\right)^{2}=$ 0 , or $f^{\prime \prime}(0)=0$.

Continuing, we obtain for $j<k$,

$$
\begin{aligned}
\left(\varphi^{\prime}(0)\right)^{k} f^{(j)}(z) & -f^{(j)}(z)\left(\varphi^{\prime}(z)\right)^{j} \\
& -(\text { terms of derivatives of } f \text { of degree }<j) \\
= & k(k-1) \cdots(k-j+1) z^{k-j},
\end{aligned}
$$

so that at $z=0,\left(\varphi^{\prime}(0)\right)^{k} f^{(j)}(0)-f^{(j)}(0)\left(\varphi^{\prime}(0)\right)^{j}=0$, or $f^{(j)}(0)=0$.

For $j=k$,

$$
\left(\varphi^{\prime}(0)\right)^{k} f^{(k)}(0)-f^{(k)}(z)\left(\varphi^{\prime}(z)\right)^{k}
$$

- (terms of derivatives of $f$ of degree $<k)=k$ ! . 
The left side of $\left({ }^{* * *}\right)$ equals 0 at $z=0$, while the right side equals $k$ !. Thus $z^{k} \notin$ range $\left(\left(\varphi^{\prime}(0)\right)^{k}-T\right)$ so that $\left(\varphi^{\prime}(0)\right)^{k} \in \sigma(T)$ for all positive integers $k$.

LEMma 3. Let $\varphi \in A,\|\varphi\| \leqq 1, \varphi(0)=0$ and $T$ be the endomorphism of $A$ induced by $\varphi$. Assume $\lambda \neq\left(\varphi^{\prime}(0)\right)^{n}$ for all positive integers $n$, and $\lambda \neq 0,1$. If $\nu$ is a positive integer, $f, g \in A$ with $(\lambda-T) f=g$ and $g(0)=g^{\prime}(0)=\cdots=g^{(\nu)}(0)=0$, then $f(0)=f^{\prime}(0)=\cdots=f^{(\nu)}(0)=0$.

Proof. Assume $\lambda f-f(\varphi)=g$ and $g(0)=g^{\prime}(0)=\cdots=g^{(\nu)}(0)=0$. Evaluating at $z=0$ gives $\lambda f(0)-f(0)=g(0)=0$, so that $f(0)=0$ since $\lambda \neq 1$.

Further, $\lambda f^{\prime}-f^{\prime}(\varphi) \varphi^{\prime}=g^{\prime}$. At $z=0$, this becomes $\lambda f^{\prime}(0)$ $f^{\prime}(0) \varphi^{\prime}(0)=g^{\prime}(0)=0$, so that $f^{\prime}(0)=0$ since $\lambda \neq \varphi^{\prime}(0)$.

In general, for $k \leqq \nu$,

$$
\lambda f^{(k)}-f^{(k)}(\varphi)\left(\phi^{\prime}\right)^{k}=g^{(k)}+\left(\text { terms in } f^{(j)}(\varphi), j<k\right) .
$$

Again evaluating at $z=0$ gives $\lambda f^{(k)}(0)-f^{(k)}(0)\left(\varphi^{\prime}(0)\right)^{k}=0$, so that $f^{(k)}(0)=0$ for $k=0,1, \cdots, \nu$, since $\lambda \neq\left(\varphi^{\prime}(0)\right)^{k}$, for all positive integers $k$.

When $g=0$, Lemma 3 can be restated as

COROLLARY 4. If $\lambda \neq\left(\varphi^{\prime}(0)\right)^{n}$ for all positive integers $n$ and $\lambda \neq$ 0,1 , then $\lambda$ is not an eigenvalue.

Lemma 5. Let $\varphi \in A,\|\varphi\| \leqq 1$ and $T$ be the endomorphism of $A$ induced by $\varphi$. If $g \in A$ and $(\lambda-T) f=g$, then

$$
\lambda^{n} f=f\left(\varphi_{n}\right)+\lambda^{n-1} g+\lambda^{n-2} g(\varphi)+\cdots+\lambda g\left(\varphi_{n-2}\right)+g\left(\varphi_{n-1}\right) .
$$

Proof. By induction on $n .\left(^{\prime}\right)$ is true for $n=1$.

Assume (') is true for $n$. Then

$$
\lambda^{n} f=f\left(\varphi_{n}\right)+\lambda^{n-1} g+\lambda^{n-2} g(\varphi)+\cdots+\lambda g\left(\varphi_{n-2}\right)+g\left(\varphi_{n-1}\right) .
$$

Also $\lambda f\left(\varphi_{n}\right)=f\left(\varphi_{n+1}\right)+g\left(\varphi_{n}\right)$ by hypothesis. Hence

$$
\lambda^{n+1} f=f\left(\varphi_{n+1}\right)+\lambda^{n} g+\lambda^{n-1} g(\varphi)+\cdots+\lambda g\left(\varphi_{n-1}\right)+g\left(\varphi_{n}\right)
$$

as needed.

LEMMA 6. Let $\varphi \in A, \varphi(0)=0$ and $\|\varphi\| \leqq 1$. If $|\boldsymbol{z}|<1$ (or, in fact, if $\left|\varphi_{j}(z)\right|<1$ for some positive integer $\left.j\right)$, then $\overline{\lim }_{k}\left|\varphi_{k}(z)\right|^{1 / k} \leqq$ $\left|\varphi^{\prime}(0)\right|$. Furthermore, (1) if $\varphi^{\prime}(0)=0$, then given $\varepsilon>0$, and $r \in[0,1)$, there exists $B>0$ so that for each positive integer $m,\left|\varphi_{m}(z)\right| \leqq B \varepsilon^{m}$ for all $z,|z| \leqq r$; (2) if $0<\left|\varphi^{\prime}(0)\right|<1$, then given $\varepsilon>0$ and $r \in[0,1)$, 
there exists $B>0$ so that for each positive integer $m,\left|\varphi_{m}(z)\right| \leqq$ $B\left((1+\varepsilon)\left|\varphi^{\prime}(0)\right|\right)^{m}$ for all $z,|z| \leqq r$.

\section{Proof.}

(i) $\varphi^{\prime}(0)=0$.

By the definition of derivative, given $\varepsilon>0$, there exists $\delta>0$ so that $|\varphi(w)| \leqq \varepsilon|w|$ for $|w|<\delta$. Using the fact that Schwarz's lemma implies $|\varphi(w)|<\delta$ when $|w|<\delta$, an induction argument shows that $\left|\varphi_{n}(w)\right| \leqq \varepsilon^{n}|w|$ for all positive integers $n$ and all $w,|w|<\delta$.

Now if $r \in[0,1)$, there is a positive integer $N$ with $\left|\varphi_{N}(z)\right|<\delta$ for all $z,|z| \leqq r$. Thus $\left|\varphi_{n+N}(z)\right|=\left|\varphi_{n}\left(\varphi_{N}(z)\right)\right| \leqq \varepsilon^{n}\left|\varphi_{N}(z)\right|$ for $|z| \leqq$ $r$, and so $\left|\varphi_{m}(z)\right| \leqq \varepsilon^{m}\left|\varphi_{N}(z) \varepsilon^{-N}\right|, m \geqq N$ when $|z| \leqq r$. Letting $B=$ $(r / \varepsilon)^{N}$ proves $(1)$.

Furthermore, since $\left|\varphi_{m}(z)\right|^{1 / m} \leqq \varepsilon B^{1 / m}$, we find $\varlimsup_{m}\left|\varphi_{m}(z)\right|^{1 / m} \leqq \varepsilon$. Since $\varepsilon$ is an arbitrary positive number, we conclude that $\lim _{m}\left|\varphi_{m}(z)\right|^{1 / m}=$ 0 .

(ii) $0<\left|\varphi^{\prime}(0)\right|<1$.

Given $\varepsilon>0$, there exists $\delta>0$ so that $|\varphi(w)| \leqq(1+\varepsilon)\left|\varphi^{\prime}(0)\right||w|$ for $|w|<\delta$. Again using Schwarz's lemma to show that $|\varphi(w)|<$ $\delta$ if $|w|<\delta$, we can show by induction that $\left|\varphi_{n}(w)\right| \leqq\left((1+\varepsilon)\left|\varphi^{\prime}(0)\right|\right)^{n}|w|$ for all positive integers $n$ and all $w,|w|<\delta$.

As before, if $r \in[0,1)$, there exists a positive integer $N$ for which $\left|\varphi_{N}(z)\right|<\delta$ for all $z,|z| \leqq r$. Thus $\left|\varphi_{n+N}(z)\right| \leqq\left((1+\varepsilon)\left|\varphi^{\prime}(0)\right|\right)^{n}\left|\varphi_{N}(z)\right|$ for $|z| \leqq r$, so that $\left|\varphi_{m}(z)\right| \leqq\left((1+\varepsilon)\left|\varphi^{\prime}(0)\right|\right)^{m}\left|\varphi_{N}(z)\right|\left((1+\varepsilon)\left|\varphi^{\prime}(0)\right|\right)^{-N}$ for $m \geqq N,|z| \leqq r$. Letting $B=\left((1+\varepsilon)\left|\varphi^{\prime}(0)\right|\right)^{-N}$ proves (2).

Also, since $\left|\varphi_{m}(z)\right|^{1 / m} \leqq B^{1 / m}(1+\varepsilon)\left|\varphi^{\prime}(0)\right|$, we find that $\overline{\lim }_{m}\left|\varphi_{m}(z)\right|^{1 / m} \leqq$ $(1+\varepsilon)\left|\varphi^{\prime}(0)\right|$. Since $\varepsilon>0$ is arbitrary, we have $\overline{\lim }_{m}\left|\varphi_{m}(z)\right|^{1 / m} \leqq$ $\left|\varphi^{\prime}(0)\right|$.

(iii) If $\left|\varphi^{\prime}(0)\right|=1$, then $\varphi(z)=c z$ for some $c,|c|=1$, and for $z \neq$ $0,\left|\varphi_{l k}(z)\right|=|z| \neq 0$, for all positive integers $k$. Clearly, $\lim _{k}\left|\varphi_{k}(z)\right|^{1 / k}=$ $1=\left|\varphi^{\prime}(0)\right|,|z| \neq 0$.

Theorem 7. Let $\varphi \in A,\|\varphi\| \leqq 1$ and $T$ be the endomorphism of $A$ induced by $\varphi$. Suppose $\varphi$ has a fixed point in the open unit disc and that the fixed set of $\phi$ is infinite. If $T$ is not an automorphism, then $\sigma(T)=\{\lambda|| \lambda \mid \leqq 1\}$.

Proof. We may assume that 0 is the fixed point of $\varphi$ and since $T$ is not an automorphism we have $\left|\varphi^{\prime}(0)\right|<1$.

Now fix a positive integer $\nu$. We show that $\sigma(T) \supset\left\{\lambda\left|\varphi^{\prime}(0)\right|^{\nu}<|\lambda|<1\right\}$.

Assume there exists $\lambda_{0} \notin \sigma(T)$ with $\left|\varphi^{\prime}(0)\right|^{\nu}<\left|\lambda_{0}\right|<1$. Then $(\lambda-T)^{-1}$ exists for $\lambda$ in a neighborhood of $\lambda_{0}$ which we assume small enough so that each $\lambda$ in this neighborhood satisfies $\left|\varphi^{\prime}(0)\right|^{\nu}<|\lambda|<1$. 
Let $g(z)=z^{\nu}$ and let $f=(\lambda-T)^{-1} g$. By Lemma 5, for each positive integer $n$, we have

$$
f(z)=f\left(\varphi_{n}(z)\right) \lambda^{-n}+\lambda^{-1} \sum_{k=0}^{n-1} g\left(\varphi_{k}(z)\right) \lambda^{-k} .
$$

Since $g(0)=g^{\prime}(0)=\cdots=g^{(\nu-1)}(0)=0$, Lemma 3 implies that $f(0)=$ $f^{\prime}(0)=\cdots=f^{(\nu-1)}(0)=0$, and so $\left|f\left(\varphi_{n}(z)\right)\right| \leqq\|f\|\left|\varphi_{n}(z)\right|^{\nu}$ for all positive integers $n$. Of course, $\left|g\left(\varphi_{k}(z)\right)\right|=\left|\varphi_{k}(z)\right|^{\nu}$ for all positive integers $k$.

Lemma 6 asserts that $\varlimsup_{n}\left|\varphi_{n}(z)\right|^{1 / n} \leqq\left|\varphi^{\prime}(0)\right|$ for all $z,|z|<1$, so that for such $z$,

$$
\varlimsup_{n}\left|f\left(\varphi_{n}(z)\right) \lambda^{-}\right|^{1 / n} \leqq \varlimsup_{n}\left(\|f\|\left|\varphi_{n}(z)^{\nu} \lambda^{-n}\right|\right)^{1 / n}\left|\left(\varphi^{\prime}(0)\right)^{\nu} \lambda^{-1}\right|<1 .
$$

Hence the first term of the right hand side of $\left(^{*}\right)$ approaches 0 as $n \rightarrow \infty$.

Furthermore, $\overline{\lim }_{k}\left|g\left(\varphi_{k}(z)\right) \lambda^{-k}\right|^{1 / k}=\overline{\lim }_{k}\left|\varphi_{k}(z)^{\nu} \lambda^{-k}\right|^{1 / k} \leqq\left|\varphi^{\prime}(0)\right|^{\nu}|\lambda|^{-1}<$ 1 so that $\sum_{k=0}^{\infty} g\left(\varphi_{k}(z)\right) \lambda^{-k}$ converges for all $z,|z|<1$. Thus for $\lambda$ in some neighborhood of $\lambda_{0}$ with $\left|\varphi^{\prime}(0)\right|^{\nu}<|\lambda|<1$,

$$
f(z)=(\lambda-T)^{-1} g(z)=\lambda^{-1} \sum_{k=0}^{\infty} g\left(\varphi_{k}(z)\right) \lambda^{-k} \text { for all } z,|z|<1 .
$$

Now let $S$ be the fixed set of $\varphi$. Since $\varphi$ is analytic on the open unit disc, $\left|\varphi^{\prime}(0)\right|<1$ and $\varphi$ maps $S$ onto itself, we can construct a sequence $\left\{x_{n}\right\}_{-\infty}^{\infty}$ in $S$ satisfying

(i) $0<\left|x_{0}\right|<1$, (ii) $\varphi\left(x_{n}\right)=x_{n+1}$, and (iii) the $x_{n}$ 's are distinct. If $x_{0}$ is fixed, then $x_{n}=\varphi_{n}\left(x_{0}\right)$ are uniquely determined for $n>0$, but unless $\varphi$ is $1-1$ on $S$, there may be many choices for $x_{-1}, x_{-2}, \cdots$.

Let $B$ be the Banach algebra of bounded functions on $\left\{x_{n}\right\}$ with component-wise addition and multiplication and sup-norm. The map $\varphi$ induces an isometric automorphism $\widetilde{T}$, say, on $B$, by $\widetilde{T} h\left(x_{n}\right)=h\left(\varphi\left(x_{n}\right)\right)=$ $h\left(x_{n+1}\right)$, for $h \in B$. For convenience, define $\varphi_{-k}$ on $\left\{x_{n}\right\}$ by $\varphi_{-k}\left(x_{n}\right)=$ $x_{n-k}$.

Now, $\sigma(\widetilde{T})=\{\lambda|| \lambda \mid=1\}$ so that if $|\lambda|<1$, then $(\lambda-\widetilde{T})^{-1}$ exists on $B$ and $F=(\lambda-\widetilde{T})^{-1} g$ (on $\left.\left\{x_{n}\right\}\right)$ satisfies

$$
\begin{aligned}
F\left(x_{0}\right)=-\widetilde{T}^{-1}\left[\left(I-\lambda \widetilde{T}^{-1}\right)^{-1} g\right]\left(x_{0}\right) & =-\widetilde{T}^{-1} \sum_{k=0}^{\infty} \lambda^{k} \widetilde{T}^{-k} g\left(x_{0}\right)=-\sum_{k=0}^{\infty} \lambda^{k} \widetilde{T}^{-(k+1)} g\left(x_{0}\right) \\
& =-\sum_{k=0}^{\infty} \lambda^{k} g\left(\varphi_{-(k+1)}\left(x_{0}\right)=-\lambda^{-1} \sum_{k=1}^{\infty} \lambda^{k} g\left(\varphi_{-k}\left(x_{0}\right)\right)\right. \\
& =-\lambda^{-1} \sum_{k=-\infty}^{-1} g\left(\varphi_{k}(x)\right) \lambda^{-k} .
\end{aligned}
$$

Therefore, for each $\lambda$ in some ball about $\lambda_{0}$, with $\left|\varphi^{\prime}(0)\right|^{\nu}<|\lambda|<$ 1 , we have 


$$
\lambda^{-1} \sum_{k=0}^{\infty} g\left(\varphi_{k}\left(x_{0}\right)\right) \lambda^{-k}=-\lambda^{-1} \sum_{k=-\infty}^{-1} g\left(\varphi_{k}\left(x_{0}\right)\right) \lambda^{-k},
$$

since both expressions represent $\left((\lambda-\widetilde{T})^{-1} g\right)\left(x_{0}\right)$.

On the other hand, $\sum_{k=-\infty}^{\infty} g\left(\mathcal{P}_{k}\left(x_{0}\right)\right) w^{-k}$ is the Laurent expansion of a function analytic in the annulus $\left\{\left.w|| \varphi^{\prime}(0)\right|^{\nu}<|w|<1\right\}$ since $\varlimsup_{k}\left|g\left(\varphi_{k}\left(x_{0}\right)\right)\right|^{1 / k}=\varlimsup_{k}\left|\left(\varphi_{k}\left(x_{0}\right)\right)^{\nu}\right|^{1 / k} \leqq\left|\varphi^{\prime}(0)\right|^{\nu}$ and $\varlimsup_{k}\left|g\left(\varphi_{-k}\left(x_{0}\right)\right)\right|^{1 / k} \leqq 1$. But (**) implies that $\sum_{k=-\infty}^{\infty} g\left(\varphi_{k}\left(x_{0}\right)\right) \lambda^{-k}=0$ in a ball about $\lambda_{0}$ and so the analytic function $\sum_{k=-\infty}^{\infty} g\left(\varphi_{k}\left(x_{0}\right)\right) w^{-k}$ is identically zero in the entire annulus $\left\{\left.w|| \varphi^{\prime}(0)\right|^{\nu}<|w|<1\right\}$. Thus $g\left(\varphi_{k}\left(x_{0}\right)\right)=0$ for all integers $k$. Since $\left\{\varphi_{k}\left(x_{0}\right)\right\}$ is infinite and $\varphi_{k}\left(x_{0}\right) \rightarrow 0$ as $k \rightarrow \infty$, the analytic function $g$ vanishes on an infinite set with 0 as a limit point. Hence $g=0$. But this contradicts the assumption that $g(z)=z^{\nu}$.

Therefore, the assumption that there exists $\lambda_{0} \notin \sigma(T)$ with $\left|\varphi^{\prime}(0)\right|^{2}<$ $\left|\lambda_{0}\right|<1$ is false. Hence $\sigma(T) \supset\left\{\left.\lambda|| \varphi^{\prime}(0)\right|^{\nu}<|\lambda|<1\right\}$. Since $\nu$ is arbitrary, $\sigma(T)=\{\lambda|| \lambda \mid \leqq 1\}$.

LeMma 8. Let $\varphi \in A,\|\varphi\| \leqq 1, \varphi(0)=0$ and $T$ be the endomorphism of $A$ induced by $\varphi$. Let $\nu$ be a positive integer. Suppose every function in $A$ with a zero of order at least $(\nu+1)$ at 0 is in the range of $(\lambda-T)$, where $\lambda \neq 0,1,\left(\varphi^{\prime}(0)\right)^{n}, n$ a positive integer. Then $1, z, z^{2}, \cdots, z^{\nu}$ are in the range of $\lambda-T$.

Proof. Let $g$ be defined on the unit disc by $g(z)=(\varphi(z))^{\nu}-$ $\left(\varphi^{\prime}(0)\right)^{\nu} z^{\nu}$. Then $g \in A$ and has a zero of order at least $(\nu+1)$ at 0 . By hypothesis we can find $h \in A$ with $(\lambda-T) h=g$. Let $f=$ $\left(\lambda-\left(\phi^{\prime}(0)\right)^{2}\right)^{-1}\left(h+z^{2}\right)$. Then

$$
\begin{aligned}
(\lambda-T) f & =\left(\lambda-\left(\varphi^{\prime}(0)\right)^{\nu}\right)^{-1}\left[(\lambda-T) h+(\lambda-T) z^{\nu}\right] \\
& =\left(\lambda-\left(\varphi^{\prime}(0)\right)^{\nu}\right)^{-1}\left[g+\lambda z^{\nu}-(\varphi(z))^{\nu}\right] \\
& =\left(\lambda-\left(\varphi^{\prime}(0)\right)^{\nu}\right)^{-1}\left[(\varphi(z))^{\nu}-\left(\varphi^{\prime}(0)\right)^{\nu} z^{\nu}+\lambda z^{\nu}-(\varphi(z))^{\nu}\right]=z^{\nu} .
\end{aligned}
$$

Thus if range $(\lambda-T)$ contains all functions with a zero of order at least $(\nu+1)$ at 0 , and if $\lambda \neq 0,1,\left(\varphi^{\prime}(0)\right)^{n}$ for all positive integers $n$, then $z^{\nu} \in$ range $(\lambda-T)$.

In the same way we can conclude, successively, that $z^{\nu-1}, z^{\nu-2}, \cdots$, $z \in$ range $(\lambda-T)$. Also $(\lambda-T)(\lambda-1)^{-1}=1$ showing that the constants are in range $(\lambda-T)$.

THEOREM 9. Let $\varphi \in A,\|\varphi\| \leqq 1$ and $T$ be the endomorphism of $A$ induced by $\varphi$. Let $z_{0}$ be a fixed point of $\varphi$ in the open unit disc and suppose $\left\{z_{0}\right\}$ is the fixed set of $\varphi$. Then $\sigma(T)=\left\{\left(\varphi^{\prime}\left(z_{0}\right)\right)^{n} \mid n\right.$ is a positive integer $\} \cup\{0,1\}$.

Proof. By Lemma 1 we may assume that $z_{0}=0$ and Lemma 2 
implies that $\sigma(T) \supset\left\{\left(\varphi^{\prime}(0)\right)^{n} \mid n\right.$ is a positive integer $\}$. Certainly 0 and 1 are in $\sigma(T)$.

We prove that $\sigma(T)=\left\{\left(\varphi^{\prime}(0)\right)^{n} \mid n\right.$ is a positive integer $\} \cup\{0,1\}$ for the case $0<\left|\varphi^{\prime}(0)\right|<1$. The case $\varphi^{\prime}(0)=0$ is entirely similar.

Since the fixed set of $\varphi$ is $\{0\}$, given $r \in(0,1)$, there exists a positive integer $m$ with $\left|\varphi_{m}(z)\right|<r$ for all $z,|z| \leqq 1$. Choose $\varepsilon>0$ so that $(1+\varepsilon)\left|\varphi^{\prime}(0)\right|<1$. Let $\nu$ be an arbitrary positive integer and consider $\lambda$ satisfying $\left((1+\varepsilon)\left|\varphi^{\prime}(0)\right|\right)^{\nu+1}<|\lambda|$.

By Lemma 6 , there exists $B_{1}>0$ so that

$\left|\varphi_{k}\left(\varphi_{m}(z)\right)\right|<B_{1}\left((1+\varepsilon)\left|\varphi^{\prime}(0)\right|\right)^{k}$ for all $z,|z| \leqq 1$, and all positive integers $k$. Hence

$\left|\varphi_{k}(z)\right|<B\left((1+\varepsilon)\left|\varphi^{\prime}(0)\right|\right)^{k}$ for all $z,|z| \leqq 1$, and all positive integers $k$, where $B=B_{1}\left((1+\varepsilon)\left|\varphi^{\prime}(0)\right|\right)^{-m}$.

Now let $g \in A$ with $g(0)=g^{\prime}(0)=\cdots=g^{(\nu)}(0)=0$. We claim that $g \in$ range $(\lambda-T)$. To see this, we observe first that $\sum_{k=0}^{\infty} g\left(\varphi_{k}(z)\right) \lambda^{-k}$ converges uniformly in $z$. Indeed, $|g(z)| \leqq\|g\||z|^{\nu+1}$ and

$$
\begin{aligned}
\left|\sum_{k=N}^{M} g\left(\varphi_{k}(z)\right) \lambda^{-k}\right| & \leqq\|g\| \sum_{k=N}^{M}\left|\varphi_{k}(z)\right|^{\nu+1}|\lambda|^{-k} \\
& \leqq\|g\| B^{\nu+1} \sum_{k=N}^{M}\left[\left((1+\varepsilon)\left|\varphi^{\prime}(0)\right|\right)^{\nu+1}|\lambda|^{-1}\right]^{k} .
\end{aligned}
$$

Since $\left((1+\varepsilon)\left|\varphi^{\prime}(0)\right|\right)^{\nu+1}<|\lambda|$, the right most term of $\left(^{*}\right)$ goes to 0 as $N, M \rightarrow \infty$.

Define $f$ on the closed unit disc by $f(z)=\lambda^{-1} \sum_{k=0}^{\infty} g\left(\varphi_{k}(z)\right) \lambda^{-k}$. Then $f \in A$ and $\lambda f(z)-f(\varphi(z))=\sum_{k=0}^{\infty} g\left(\varphi_{k}(z)\right) \lambda^{-k}-\lambda^{-1} \sum_{k=0}^{\infty} g\left({ }_{k+1}(z)\right) \lambda^{-k}=$ $g(z)$.

Hence, if $\left((1+\varepsilon)\left|\phi^{\prime}(0)\right|\right)^{\nu+1}<|\lambda|<1$ and $g$ has a zero of order at least $(\nu+1)$ at 0 , then $g \in$ range $(\lambda-T)$. By the preceding lemma, if $\lambda$ also is not equal to $0,1,\left(\varphi^{\prime}(0)\right)^{n}$ for positive integers $n$, then $1, z, \cdots, z^{\nu}$ also belong to range $(\lambda-T)$.

Now, every $h \in A$ may be written as

$$
h(z)=\left(h(0)+h^{\prime}(0) z+\cdots+\frac{h^{(\nu)}(0}{\nu !} z^{\nu}\right)+g(z)
$$

where

$$
g(z)=\left(h(z)-h(0)-h^{\prime}(0) z-\cdots-\frac{h^{(\nu)}(0)}{\nu !} z^{\nu}\right) .
$$

Clearly, $g(0)=g^{\prime}(0)=\cdots=g^{(\nu)}(0)$. As we have shown, $g \in$ range $(\lambda-T)$ when $|\lambda|>\left((1+\varepsilon)\left|\varphi^{\prime}(0)\right|\right)^{\nu+1}$. Also, if $\lambda \neq 0,1,\left(\phi^{\prime}(0)\right)^{n}, n$ a positive integer, then $1, z, \cdots, z^{\nu} \in$ range $(\lambda-T)$. Thus, for these $\lambda$, every $h$ in $A$ is in the range of $(\lambda-T)$, so $(\lambda-T)$ is onto. Also, by Corollary $4,(\lambda-T)$ is $1-1$ if $\lambda \neq 0,1,\left(\varphi^{\prime}(0)\right)^{n}, n$ a positive integer. 
Hence, $(\lambda-T)^{-1}$ exists for all $\lambda,|\lambda|>\left((1+\varepsilon)\left|\varphi^{\prime}(0)\right|\right)^{\nu+1}$ and $\lambda \neq 0,1$, $\left(\varphi^{\prime}(0)\right)^{n}, n$ a positive integer. Since $\nu$ is arbitrary, we conclude that if $\lambda \neq 0,1,\left(\Phi^{\prime}(0)\right)^{n}, n$ a positive integer, then $\lambda \notin \sigma(T)$.

As we noted, Lemma 2 shows that for each positive integer $n$, $\left(\varphi^{\prime}(0)\right)^{n}$ is in $\sigma(T)$. Since 0 and 1 are in $\sigma(T), \sigma(T)=\left\{\varphi^{\prime}(0)\right)^{n} \mid n$ is a positive integer $\} \cup\{0,1\}$.

The case when $\varphi^{\prime}(0)=0$ is similar. We just replace $(1+\varepsilon)\left|\varphi^{\prime}(0)\right|$ by $\varepsilon$.

To summarize, we have shown that if $T$ is the endomorphism of $A$ induced by $\varphi \in A,\|\varphi\| \leqq 1$, and if there is a fixed point $z_{0}$ of $\varphi$ in the open unit disc, then the spectrum of $T$ is determined as follows.

(1) If $\phi$ is schlicht and onto, then $T$ is an automorphisms and $\sigma(T)$ is the closure of $\left\{\left(\varphi^{\prime}\left(z_{0}\right)\right)^{n} \mid n\right.$ is a positive integer $\}$. We have seen that $\sigma(T)$ is contained in the unit circle and that $\sigma(T)$ may be finite.

(2) If $T$ is not an automorphism, but the fixed set of $\varphi$ is infinite, then Theorem 7 shows that $\sigma(T)=\{\lambda|| \lambda \mid \leqq 1\}$.

(3) If the fixed set of $\varphi$ consists of the single point $z_{0}$ in the open unit disc, then Theorem 9 shows that $\sigma(\sigma)=\left\{\left(\varphi^{\prime}\left(z_{0}\right)\right)^{n} \mid n\right.$ is a positive integer $\} \cup\{0,1\}$.

Some simple examples of the various types of endomorphisms we have discussed are (i) $T$ is induced by a linear fractional transformation $\varphi$ of the unit disc onto itself. Then $T$ is an automorphism and $\sigma(T)=$ closure $\left\{\left(\varphi^{\prime}\left(z_{0}\right)\right)^{n} \mid n\right.$ is a positive integer $\}$ where $\left|z_{0}\right|<1$ and $\varphi\left(z_{0}\right)=z_{0}$. If $\varphi$ is normalized to have $z_{0}=0$, then $\varphi$ has the form $\varphi(z)=c z,|c|=1$. Here, $\sigma(T)=\{\lambda|| \lambda \mid=1\}$ if $c$ is not a root of unity; otherwise, if $c^{n}=1, \sigma(T)=\left\{1, c, \cdots c^{n-1}\right\}$.

(ii) $T$ is induced by $\varphi(z)=\left(z+z^{2}\right) / 2$. Here one can show that the fixed set is infinite and hence $\sigma(T)=\{\lambda|| \lambda \mid \leqq 1\}$.

(iii) $T$ is induced by $\varphi(z)=\left(z+z^{2}\right) / 4$. Here the fixed set of $\varphi$ is $\{0\}, \varphi^{\prime}(0)=1 / 4$, and so $\sigma(T)=\left\{4^{-n} \mid n\right.$ is a nonnegative integer $\} \cup$ $\{0\}$.

(iv) $T$ is induced by $\varphi(z)=c z^{k}, k$ a positve integer $>1$. If $|c|=$ 1 , then the fixed set of $\varphi$ is the entire disc and $\sigma(T)=\{\lambda|| \lambda \mid \leqq 1\}$, while if $|c|<1$, then the fixed set of $\varphi$ is $\{0\}$ and $\sigma(T)=\{0,1\}$.

As a final remark, the question of determining the spectra of endomorphisms induced by $\varphi \in A$ with fixed points only on the unit circle is still open. Again the spectra seem to depend on the fixed set of $\varphi$, but only partial results have been obtained.

Received September 15, 1971. Partially supported by NSF grant GP 11281. 


\section{PACIFIC JOURNAL OF MATHEMATICS}

\section{EDITORS}

D. Gilbarg and J. Milgram

Stanford University

Stanford, California 94305

\author{
R. A. Beaumont \\ University of Washington \\ Seattle, Washington 98105
}

J. DuGUNDJI

Department of Mathematics

University of Southern California

Los Angeles, California 90007

Richard ARENS

University of California

Los Angeles, California 90024

\section{ASSOCIATE EDITORS}
E. F. BECKENBACH
B. H. NeumanN
F. WOLF
K. YosHIDA

\section{SUPPORTING INSTITUTIONS}

UNIVERSITY OF BRITISH COLUMBIA

CALIFORNIA INSTITUTE OF TECHNOLOGY

UNIVERSITY OF CALIFORNIA

MONTANA STATE UNIVERSITY

UNIVERSITY OF NEVADA

NEW MEXICO STATE UNIVERSITY

OREGON STATE UNIVERSITY

UNIVERSITY OF OREGON

OSAKA UNIVERSITY

\author{
UNIVERSITY OF SOUTHERN CALIFORNIA \\ STANFORD UNIVERSITY \\ UNIVERSITY OF TOKYO \\ UNIVERSITY OF UTAH \\ WASHINGTON STATE UNIVERSITY \\ UNIVERSITY OF WASHINGTON
* * * *
AMERICAN MATHEMATICAL SOCIETY \\ NAVAL WEAPONS CENTER
}

The Supporting Institutions listed above contribute to the cost of publication of this Journal, but they are not owners or publishers and have no responsibility for its content or policies.

Mathematical papers intended for publication in the Pacific Journal of Mathematics should be in typed form or offset-reproduced, (not dittoed), double spaced with large margins. Underline Greek letters in red, German in green, and script in blue. The first paragraph or two must be capable of being used separately as a synopsis of the entire paper. The editorial "we" must not be used in the synopsis, and items of the bibliography should not be cited there unless absolutely necessary, in which case they must be identified by author and Journal, rather than by item number. Manuscripts, in duplicate if possible, may be sent to any one of the four editors. Please classify according to the scheme of Math. Rev. Index to Vol. 39. All other communications to the editors should be addressed to the managing editor, Richard Arens, University of California, Los Angeles, California, 90024.

50 reprints are provided free for each article; additional copies may be obtained at cost in multiples of 50 .

The Pacific Journal of Mathematics is issued monthly as of January 1966. Regular subscription rate: $\$ 48.00$ a year (6 Vols., 12 issues). Special rate: $\$ 24.00$ a year to individual members of supporting institutions.

Subscriptions, orders for back numbers, and changes of address should be sent to Pacific Journal of Mathematics, 103 Highland Boulevard, Berkeley, California, 94708.

PUBLISHED BY PACIFIC JOURNAL OF MATHEMATICS, A NON-PROFIT CORPORATION

Printed at Kokusai Bunken Insatsusha (International Academic Printing Co., Ltd.), 270, 3-chome Totsuka-cho, Shinjuku-ku, Tokyo 160, Japan. 


\section{Pacific Journal of Mathematics}

\section{Vol. 46, No. 2 December, 1973}

Christopher Allday, Rational Whitehead products and a spectral sequence of



James Edward Arnold, Jr., Attaching Hurewicz fibrations with fiber



Catherine Bandle and Moshe Marcus, Radial averaging transformations with various metrics.................................

David Wilmot Barnette, A proof of the lower bound conjecture for convex

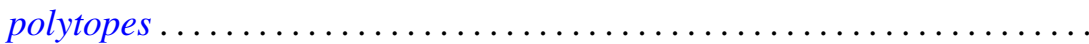

Louis Harvey Blake, Simple extensions of measures and the preservation of

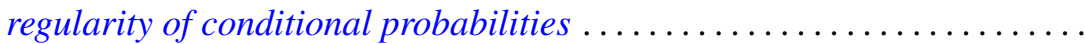

James W. Cannon, New proofs of Bing's approximation theorems for

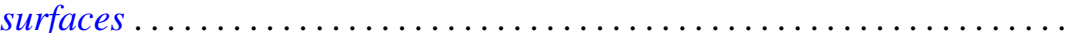

C. D. Feustel and Robert John Gregorac, On realizing HNN groups in

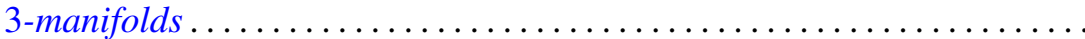

Theodore William Gamelin, Iversen's theorem and fiber algebras . . . . . . . . 389

Daniel H. Gottlieb, The total space of universal fibrations . . . . . . . . . . . .

Yoshimitsu Hasegawa, Integrability theorems for power series expansions of



Dean Robert Hickerson, Length of period simple continued fraction expansion of $\sqrt{ } d$

Herbert Meyer Kamowitz, The spectra of endomorphisms of the disc algebra.

Dong S. Kim, Boundedly holomorphic convex domains

Daniel Ralph Lewis, Integral operators on $\mathscr{L}_{p}$-spaces ...

John Eldon Mack, Fields of topological spaces . . . . . . . . .

V. B. Moscatelli, On a problem of completion in bornology

Ellen Elizabeth Reed, Proximity convergence structures. .

Ronald C. Rosier, Dual spaces of certain vector sequence spaces .

Robert A. Rubin, Absolutely torsion-free rings

Leo Sario and Cecilia Wang, Radial quasiharmonic functions . .

James Henry Schmerl, Peano models with many generic classes .

H. J. Schmidt, The $\mathscr{F}$-depth of an $\mathscr{F}$-projector ............

Edward Silverman, Strong quasi-convexity. . . . . . . . . . . . . . . . . 549

Barry Simon, Uniform crossnorms ....................... 555

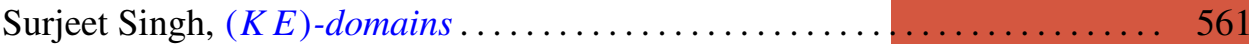

Ted Joe Suffridge, Starlike and convex maps in Banach spaces . . . . . . . . 575

Milton Don Ulmer, $C$-embedded $\Sigma$-spaces . . . . . . . . . . . . . . . . 591

Wolmer Vasconcelos, Conductor, projectivity and injectivity . . . . . . . . . 603 